\title{
Choice of control population in studies of adverse reproductive effects of occupational exposures and its effect on risk estimates
}

\author{
K SHEIKH \\ From the Department of Epidemiology, University of Michigan, School of Public Health, Ann Arbor, \\ MI 48109, USA.
}

ABSTRACT Cohort studies of adverse reproductive effects of occupational exposures that compare the outcome of exposed pregnancies with non-exposed pregnancies among the same group of ${ }_{-}^{\rightarrow}$ mothers (internal controls) and among a different group of mothers (external controls) have beenis reviewed. Confounding of the hypothesised associations by parental characteristics, the outcome of $\overrightarrow{+}$ previous pregnancies, and other exposures is not adequately assessed in these studies. The risk of an음 adverse outcome appears to be consistently higher among the external control group of pregnanciesthan among the internal controls. If the differences between the two control groups are real, com- -0 parisons based on external controls underestimate the relative or attributable risk. Alternative explanation for this phenomenon are discussed. A likely explanation is a misclassification of $\vec{\infty}$ exposure or a high prevalence of risk factors other than the exposure of interest among the external. ${ }^{.}$ controls. Non-exposed pregnancies among exposed mothers may be used for comparison in preference to pregnancies among non-exposed mothers.

The consideration of factors involved in the selection of study populations is essential for evaluating the validity of aetiological associations. Selection bias in occupational cohort studies using the general population as reference, known as the "healthy worker effect," is well recognised. A similar selection process may also operate in occupational reproductive epidemiology. ${ }^{1}$ Investigations of adverse reproductive effects of occupational exposure are usually cohort studies since the study populations are defined by exposures. ${ }^{2}$ Often, the study cohort is historical. The choice for a comparison population is between an occupational or a non-occupational group. Since the index subject in studies of pregnancy outcome is the fetus (or pregnancy), an additional comparison group, sib-fetuses from the same parenthood that are not exposed, is also available. There are certain advantages and disadvantages in using non-exposed sib-fetuses as a control group.

The present paper reviews several studies of fetal death, birth weight, and birth defects in live births in relation to a variety of occupational exposures in an attempt to assess the comparability of different control populations. In each example the risk of death during intrauterine life or retarded growth (indicated

Accepted 8 July 1986 by low birth weight) among a group of exposed $\stackrel{0}{\frac{0}{\varnothing}}$ fetuses is compared with that in two non-exposed 0 control groups of fetuses. The first control group is $\overrightarrow{\overrightarrow{0}}$ the fetuses conceived by the parents of exposed 3 fetuses (the "internal comparison" group) whereas the second group of control fetuses is conceived by parents who are presumed to have never been ${ }_{\Phi}$ exposed (the "external comparison" group) to the exposure of interest.

Anaesthetic agents are the occupational exposures most extensively investigated in relation to adverseô outcomes of pregnancy. Vessey has reviewed 243 selected studies of fetal death and birth defects among음 the offspring of physicians, nurses, and technicians, $D$ some of whom had been occupationally exposed to을. anaesthetic agents. ${ }^{3}$ Of these 24 studies, 15 had only one (internal or external) control group of fetuses. In four of the nine studies with both internal and exter- $N$ nal controls there was no association between the $\mathrm{N}_{\mathrm{N}}$ occupational exposure and an adverse outcome of pregnancy. Hence, the risks in the two control groupse were similar. One of the positive studies in which the rate/ratio of the outcome among the internal controls $\stackrel{\infty}{+}$ differed from that among the external controls is illus- 0 trated below as an example. A publications search forō뭉 studies of adverse reproductive effects of occupational exposures other than anaesthetic agents 
Table 1 Outcome of pregnancy among British physicians

\begin{tabular}{|c|c|c|c|}
\hline & \multicolumn{2}{|c|}{ Anaesthetists } & \multirow{2}{*}{$\begin{array}{l}\text { Other } \\
\text { physicians }\end{array}$} \\
\hline & Exposed & Non-exposed & \\
\hline $\begin{array}{l}\text { No of pregnancies } \\
\text { Spontaneous abortions (\%) } \\
\text { No of live births } \\
\text { Birth defects }(\%)\end{array}$ & $\begin{array}{l}737 \\
18 \cdot 2 \dagger \\
599 \\
6 \cdot 5 \dagger\end{array}$ & $\begin{array}{c}336 \\
13 \cdot 7 \\
284 \\
2 \cdot 5 \dagger\end{array}$ & $\begin{array}{c}2150 \\
14 \cdot 7 \dagger \\
1817 \\
4 \cdot 9\end{array}$ \\
\hline
\end{tabular}

*Worked as anaesthetists at the time of conception and during pregnancy.

†Significant difference, $\mathrm{p}<0.025$

Adapted from Knill-Jones, et al. ${ }^{4}$

found that in many studies there was either no control group or the exposure of interest was not specified. In seven studies occupational exposures were specified but there was only one control group. The four studies with both internal and external controls are briefly described below.

\section{Example 1}

In 1971, 1241 female anaesthetists and a sample of non-anaesthetist female physicians were surveyed in the United Kingdom. Approximately $81 \%$ of the physicians responded to a postal questionnaire and provided their obstetric and occupational histories. ${ }^{4}$ The non-anaesthetist physicians (external controls) were on the average 2.5 years older than the anaesthetists. The respondent anaesthetists reported 737 pregnancies when they were working as anaesthetists (exposed pregnancies) and 336 pregnancies when not working as anaesthetists (non-exposed pregnancies, internal controls). The numbers of pregnancies, spontaneous abortions, live births, and birth defects among live births, reported by the 563 anaesthetists and 828 controls are given in table 1 . Spontaneous abortions as a proportion of all pregnancies and birth defects as a proportion of all live births were highest among exposed pregnancies and lowest among nonexposed pregnancies reported by the anaesthetists.

\section{Example 2}

Infante et al compared the frequency of fetal deaths in the wives of workers exposed to vinyl chloride monomer (VCM) with fetal deaths in the wives of polyvinyl chloride (PVC) fabrication and rubber workers (external controls). ${ }^{5}$ The external controls, known to have had low or no exposure to VCM, were matched with VCM workers by age. Fetal deaths presumably included induced abortions and still births. Ninety five VCM workers and 158 external controls were interviewed to ascertain their wives' obstetric histories. The wives of $70 \mathrm{VCM}$ workers had been pregnant before the men were exposed to VCM (non-exposed pregnancies, internal controls) and the wives of 62 VCM workers had conceived after the men were exposed to VCM (exposed pregnancies). Similarly, the wives of 95 and 113 age matched external control workers had been pregnant respectively before and after the VCM workers were exposed to VCM. Table 2 shows the numbers of exposed (to VCM) and nonexposed pregnancies (fetuses) and fetal deaths among the wives of the two groups of workers, excluding the pregnancies among women who experienced three or more fetal deaths. The fetal death ratio, adjusted for paternal age, is highest among the VCM exposed pregnancies and lowest among the pregnancies of VCM workers' wives before they were exposed to VCM (internal controls). Similar trends were observed when pregnancies among women who experienced three or more fetal deaths were included in the analysis. ${ }^{5}$

\section{Example 3}

The fetotoxic effects of occupational exposure to ethylene oxide among Finnish hospital female staff were reported by Hemminki et al. ${ }^{6}$ Obstetric histories from an unknown number of sterilising staff and nursing auxiliaries were obtained by self administered questionnaires and information on exposure to ethylene oxide during pregnancy was provided by their

Table 2 Fetal deaths among low risk* wives of chemical and rubber workers according to vinyl chloride monomer (VCM) exposure

\begin{tabular}{|c|c|c|c|c|}
\hline & \multicolumn{2}{|l|}{ Pre-exposure } & \multicolumn{2}{|l|}{ Post-exposure } \\
\hline & VCM workers & Rubber workers & VCM workers & Rubber workers $\dagger$ \\
\hline $\begin{array}{l}\text { Mean paternal age at conception } \\
\text { No of pregnancies among wives } \\
\text { Fetal deaths }(\%) \\
\text { Age adjusted fetal deaths (\%) }\end{array}$ & $\begin{array}{c}26 \cdot 3 \\
141 \\
6 \cdot 4 \\
3 \cdot 1\end{array}$ & $\begin{array}{c}23 \cdot 0 \\
159 \\
6.9 \\
6.9\end{array}$ & $\begin{array}{l}30 \cdot 8 \\
120 \\
11 \cdot 7 \\
10 \cdot 8\end{array}$ & $\begin{array}{l}30 \cdot 2 \\
265 \\
6 \cdot 8 \\
6 \cdot 8\end{array}$ \\
\hline
\end{tabular}

* Excluding women who reported three or more fetal deaths.

†Includes PVC fabrication workers.

Adapted from Infante $e t$ al. ${ }^{5}$ 
Table 3 Spontaneous abortions among sterilising staff (SS) and nursing auxiliaries (NAs) employed at hospitals in Finland in relation to exposure to ethylene oxide (EO)

\begin{tabular}{llcc}
\hline & $\begin{array}{l}\text { SS } \\
\text { exposed } \\
\text { to EO }\end{array}$ & $\begin{array}{l}\text { SS not } \\
\text { exposed } \\
\text { to EO }\end{array}$ & $\begin{array}{l}\text { NAs not } \\
\text { exposed } \\
\text { to EO }\end{array}$ \\
\hline $\begin{array}{l}\text { No of pregnancies } \\
\begin{array}{l}\text { Spontaneous abortions (\%) } \\
\text { Adjusted* spontaneous }\end{array}\end{array}$ & $\begin{array}{l}82 \\
20.7\end{array}$ & $\begin{array}{c}1068 \\
10.3\end{array}$ & $\begin{array}{c}1179 \\
10.6\end{array}$ \\
\begin{tabular}{l} 
abortions (\%) \\
\hline
\end{tabular} & $16.1 \dagger$ & $7.8 \dagger$ & $10.5 \dagger$
\end{tabular}

*Adjusted for maternal age at conception, parity, decade of pregnancy, smoking, and coffee and alcohol consumption. tSignificantly different, $\mathrm{p}<0.001$.

Adapted from Hemminki et al. ${ }^{6}$

supervising nurses. The sterilising staff reported 82 pregnancies during which they (their fetuses) were exposed to ethylene oxide and 1068 pregnancies during which they were not exposed (internal controls). The nursing auxiliaries, who were assumed not to be exposed to ethylene oxide reported 1179 pregnancies (external controls). The spontaneous abortion ratios, adjusted for maternal age at conception, parity, calendar decade of pregnancy, prevalence of smoking, and coffee and alcohol consumption among the three groups are given in table 3. The highest proportion of spontaneously aborted pregnancies is among the exposed and the lowest among the internal controls.

\section{Example 4}

In another Finnish study abortions among 67 female lamination workers employed at six plants manufacturing reinforced polyester plastic products were compared with abortions among an equal number of female textile and food production workers (external controls). ${ }^{7}$ The controls were matched with lamination workers by age and the two groups of women were similar with respect to social class. Obstetric and occupational histories were obtained from the study population at interviews. Table 4 gives the numbers of pregnancies and abortions among the lamination workers before and during occupational exposure to styrene. The obstetric histories of the external control women are given in the table to correspond with the exposure periods of age matched lamination workers? The frequency of induced abortion dramatically increased during exposure to styrene. Among the lamination workers, abortion was induced in eight of 16 pregnancies (table 4). Because of the pronounced variability in the frequency of induced abortions, half the number of induced abortions have been sub- $\mathbb{Q}$ tracted from the denominators in calculating spontaneous abortion ratios. ${ }^{8}$ The numbers of events in thisstudy are too small to be of statistical significance, but the data suggest that the highest spontaneous abor $-\vec{\omega}$ tion ratio is for the pregnancies among the lamination

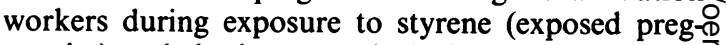
nancies) and the lowest ratio is for the pregnancies among the same group of women before exposure to $\vec{f}$ styrene (internal controls).

\section{Example 5}

In a recent study Taylor et al investigated fetal growth ${ }_{\rightarrow}^{-}$ retardation in relation to the level of cumulativeo occupational exposure to polychlorinated biphenyls (PCBs). ${ }^{9}$ Personnel records in two capacitor manu- $\overrightarrow{0}$ facturing facilities in New York State were reviewed. and 354 female workers were identified as having been pregnant between 1958 and 1975. Thirty nine women had worked in "high-exposure" areas (direct contact with PCBs) and 280 in "low-exposure" areas@ (PCBs not directly used). A total of 388 pregnancies among these women resulted in live, singleton births. Birth weights and maternal characteristics were을 obtained from birth certificates. A sample of 388 con- $\frac{3}{3}$ trols matched on maternal age, parity, and the year of birth was selected from singleton live births in two surrounding counties. These external control live births were regarded as not exposed to high levels of $\exists$ PCBs during intrauterine life. Birth weight was highest among those live births who were exposed to low levels of PCBs (internal controls), and lowest 0 among those exposed during intrauterine life to high levels of PCBs (table 5). Adjustments for maternal 윽 age, parity, year of birth, and sex of the newborn did

Table 4 Abortions among 67 female lamination workers exposed to styrene and 67 textile or food production workers (controls)

\begin{tabular}{|c|c|c|c|c|}
\hline & \multicolumn{2}{|c|}{ Before styrene exposure } & \multicolumn{2}{|c|}{ During styrene exposure } \\
\hline & Lamination workers & Controls & Lamination workers & Controls \\
\hline $\begin{array}{l}\text { Women (n) } \\
\text { Pregnancies (n) } \\
\text { Induced abortions (n) } \\
\text { Spontaneous abortions (n) } \\
\text { Spontaneous abortion ratio* }(\%)\end{array}$ & $\begin{array}{l}48 \\
84 \\
7 \\
8 \\
9 \cdot 9\end{array}$ & $\begin{array}{c}48 \\
80 \\
5 \\
8 \\
10 \cdot 3\end{array}$ & $\begin{array}{c}12 \\
16 \\
8 \\
4 \\
33 \cdot 3\end{array}$ & $\begin{array}{r}20 \\
22 \\
4 \\
4 \\
20 \cdot 0\end{array}$ \\
\hline
\end{tabular}


Table 5 Birth weight of children born to 354 women according to the level of exposure to polychlorinated biphenyls (PCBs) and 388 control children

\begin{tabular}{|c|c|c|c|c|}
\hline & \multicolumn{4}{|c|}{ Exposure to PCBs } \\
\hline & \multicolumn{2}{|l|}{ Low } & \multicolumn{2}{|l|}{ High } \\
\hline & Exposed & Controls & Exposed & Controls \\
\hline $\begin{array}{l}\text { No of live births } \\
\text { Mean birth weight }(g \pm S D) \\
\text { Difference in means } \\
\text { ( } 90 \% \text { Confidence interval) }\end{array}$ & \multicolumn{2}{|c|}{$\begin{array}{c}66 \\
(1 \text { to } 177)\end{array}$} & $\begin{array}{c}51 \\
3193\end{array}$ & $\begin{array}{r}51 \\
3288\end{array}$ \\
\hline
\end{tabular}

Adapted from Taylor et al. ${ }^{9}$

not materially change the difference between mean birth weights of low and high PCBs exposure category births. ${ }^{9}$

\section{Discussion}

In each of the first four examples there were two control groups of pregnancies or fetuses - an internal control group of unexposed pregnancies among the same group of women who also reported the exposed pregnancies and an external control group of supposedly non-exposed pregnancies among a separate group of women. The observed fetal death or birth defects ratio for the external control group was consistently higher than the ratio for the internal control group (tables 1-4). In the last example the exposed and the internal control groups of pregnancies came from two different groups of women. But it is interesting to note that the mean birth weight of the external control group of live births was lower than the mean birth weight of the internal control group (table 5). In other words, the risk of an adverse outcome of pregnancy appears to be greater among the external controls than among the internal controls. There may be several possible explanations for the apparent differences between the two control groups in these studies.

The number of studies reviewed is small, and the differences between the two control groups in each study may simply be a chance occurrence. For example, in the five positive studies of hospital personnel exposed to anaesthetic agents with two control groups that were reviewed by Vessey, the rate of an adverse outcome of pregnancy was higher among the internal controls than among the external controls in two studies, the rate was lower among the internal controls than among the external controls in two studies, and in one study the rates were similar. ${ }^{3}$ In all the four studies of occupational exposures other than anaesthetic agents reviewed here, however, the risk is consistently lower among the internal controls than the external controls (tables 2-5).

In one study (example 2) the frequencies of the out- come of interest were adjusted only for paternal age at conception. The spontaneous abortion ratios in the study of Finnish hospital employees (example 3) were adjusted for maternal age, parity, decade of pregnancy, smoking, and coffee and alcohol consumption. The effects of maternal age, parity, and the year of birth were controlled in the last example. Confounding by other known risk factors, such as maternal medical history and adverse outcome of previous pregnancies, was not assessed in these studies. In the two remaining studies (examples 1 and 4) there was no control for confounding in the analyses. Inadequate control for confounding may explain the apparent differences between the control groups. Furthermore, most of these studies had other methodological flaws that might have biased the results. ${ }^{1011}$

In the first four examples reproductive and occupational histories were obtained by self administered questionnaires or at interviews. ${ }^{4-7}$ It may be that the ever exposed respondents attributed adverse outcomes of truly non-exposed pregnancies to occupational exposures, thereby underestimating the risk before exposure period (in internal control group of fetuses). Reproductive and occupational histories are generally obtained separately, however, and the exposure status of each reported pregnancy (fetus) in these studies was assigned by the study personnel not by the respondents. Besides, if such a bias existed there is no reason to speculate that it was differential. The control (non-exposed) respondents were also employed during some of the reported pregnancies and may have been exposed to other fetotoxic agents. For example, in Infante's study of VCM workers (example 2) the external controls were rubber and PVC fabrication workers exposed to a variety of chemicals other than VCM. Biased recall of study exposure during affected pregnancies is, therefore, not a likely explanation for the observed differences between the two control groups.

An alternative explanation may be a misclassification of exposure in the external control group or a higher prevalence of an unknown risk factor among the external controls than among the internal controls. For example, in the study of hospital employees 
in Finland it may be that during some of the reported pregnancies the nursing auxiliaries (external controls) were knowingly or unknowingly exposed to EO or some other fetotoxic agent-such as anaesthetic agents, cytotoxic drugs, and radiation-whereas the pregnancies reported by the sterilising staff were correctly classified as exposed or non-exposed (internal controls). ${ }^{6}$ It appears that inappropriate (external) control groups were probably selected in these studies. This may also explain an inverse association or no association between occupational exposures to organic chemicals and the risk of spontaneous abortion in studies using only external controls. ${ }^{1213}$

A major problem in studies of pregnancy outcome is that the effects of parental characteristics, the outcome of previous pregnancies, and non-occupational exposures are greater than the effects of occupational exposures. ${ }^{14}$ Inadequate assessment and control for confounding, therefore, leads to spurious (negative or positive) associations. A greater problem is the effects of unknown or unmeasurable risk factors or confounders. It may be argued that non-exposed pregnancies among the same group of mothers (internal controls) who provide exposed pregnancies for study would be more comparable than non-exposed pregnancies among a different group of mothers (external controls). ${ }^{14}$ This concept may be appreciated only when it is realized that the index subject under study is the embryo or fetus, and not the parent; an exposed fetus and a non-exposed fetus may come from the same mother. The risk of morbidity (retarded growth or birth defect) or mortality (spontaneous abortion or still birth) in relation to intrauterine exposures may then be examined among a population of fetuses some of whom may share the same parents. This situation is analogous to studies of children or even adults related to each other-that is, having common family histories. Current or previous family history of disease, defect, or death is treated as a risk factor. The family history may be of an acute infectious disease, a genetic disorder, coronary heart disease, or breast cancer.

It is often argued that non-exposed pregnancies from mothers who provide exposed pregnancies cannot be used as controls because pregnancies in a woman are interdependent. The undisputed interdependence implies that a fetus is at a greater risk of dying during intrauterine life if his sibling died during fetal life, or a fetus is at a greater risk of being malformed if his sibling was born with a defect or died before birth as a result of gross malformation. But appropriate adjustments in the analyses may be made for all these risk factors and for variable paternal age, medical history, or non-occupational exposures. In fact, non-exposed sib-fetuses may be more comparable than non-exposed unrelated fetuses because the former share with the exposed sib-fetuses common $\frac{3}{\infty}$

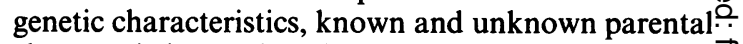
characteristics, and environment.

Another argument against the use of internal con $=\frac{\text { ? }}{\frac{7}{0}}$ trols is that high parity and older maternal age are등 risk factors for spontaneous abortion ${ }^{15}$; thus if the $\frac{\bar{c}}{6}$. later pregnancies in a woman are exposed and the $\widetilde{\Phi}^{\circ}$ earlier pregnancies are non-exposed an increased risk of spontaneous abortion associated with the exposure may be due to high parity and older maternal age. $\overrightarrow{0}$ High parity, in fact, is associated with a low risk of spontaneous abortion, but high gravidity and low $\vec{\rho}$ pregnancy order are associated with an increased risk of spontaneous abortion. ${ }^{16}$ The relation between $\frac{\mathbb{D}}{3}$ increasing maternal age and the risk of spontaneous abortion is far from straightforward. Women at high risk of spontaneous abortion tend to compensate for their losses by having more pregnancies than women + at low risk, and the more pregnancies a woman haso the older she gets. ${ }^{17}$ In any case, if maternal age, parity, gravidity, or pregnancy order confound an association appropriate adjustments for these vari-을. ables may be made in a multivariate analysis.

In certain populations women with a successful $\ddot{\infty}$ pregnancy tend to quit gainful employment and those. who have spontaneous abortions tend to continue? working. ${ }^{18}$ Consequently, active female employees tend to be multigravida and a high risk (of spontane- $\bar{O}$ ous abortion) group. In these women previous (nonexposed) pregnancies would have been spontaneously $\stackrel{\unrhd}{\unrhd}$ aborted. If the outcome of their non-exposed preg- $\overrightarrow{\vec{A}}$ nancies is compared with their exposed pregnancies $\frac{}{3}$ the relative risk would be biased toward the null. On the other hand, women who have had one or more spontaneous abortions may quit work, so that their subsequent high risk pregnancies would tend to be $\frac{\Phi}{3}$ non-exposed. Some women start work after having one or two children; their subsequent (low risk) preg- 3 . nancies would tend to be exposed. Similar attitudes toward work in relation to obstetric history may be $\frac{\rho}{3}$ prevalent in non-exposed (external control) groups of $\circ$ women. Consequently, an external control group need not necessarily be advantageous. An external $\frac{D}{0}$ control group would be indicated, however, if previous non-exposed pregnancies in a group of working $N$ women were predominantly successful or predom- $N$ inantly unsuccessful.

It appears that the choice of control population $\stackrel{N}{\omega}$ may have serious impact on risk estimates. If the differences between the internal and external controls $\varrho$ are real and not an artifact of confounding, $\mathscr{D}$ misclassification, or chance then the outcome of pregnancy among the external controls would give misleading estimates of the relative risk or attributable $\frac{D}{\mathbb{D}}$ risk. In the study of hospital employees in Finland, ${ }^{6} \stackrel{\bigcirc}{\varnothing}$ for example, the use of spontaneous abortion ratio 
for the external controls gives a relative risk (RR) of 1.5 and risk difference (RD) of $5.6 \%$, whereas the use of spontaneous abortion ratio for the internal controls gives a RR of $2 \cdot 1$ and RD of $8.3 \%$. In other words, the risk of spontaneous abortion among the external control group underestimates RR and attributable risk associated with exposure to ethylene oxide by about $30 \%$.

It is concluded that non-exposed pregnancies may be more comparable to exposed pregnancies among the same group of mothers than non-exposed pregnancies among an external control group, and that risk estimates based on external comparisons may be biased toward the null. A second control group is desirable, however, since the internal controls may not provide an entirely satisfactory basis for comparison. A variety of comparisons often strengthen the evaluation of an aetiological association. In any case, confounding of observed associations by factors known to influence the outcome of pregnancy should always be adequately assessed.

\section{References}

1 Hemminki K, Niemi ML, Kyyronen P, Kilpikari I, Vainio H Spontaneous abortions and reproductive selection mechanisms in the rubber and leather industry in Finland. $\mathrm{Br} J$ Ind Med 1983;40:81-6.

2 Selevan SG. Design considerations in pregnancy outcome studies of occupational populations. Scand J Work Environ Health 1981;7(suppl 4):76-82.

3 Vessey MP. Epidemiological studies of the occupational hazards of anaesthesia-a review. Anaesthesia 1978;33:430-8.

4 Knill-Jones RP, Rodrigues LV, Moir DD, Spence AA. Anaesthetic practice and pregnancy: controlled survey of women anaesthetists in the United Kingdom. Lancet 1972;i:1326-8.

5 Infante PF, Wagoner JK, McMichael AJ, Waxweiler RJ, Falk H. Genetic risks of vinyl chloride. Lancet 1976;i:734-5.

6 Hemminki K, Mutanen P, Saloniemi I, Niemi ML, Vainio H. Spontaneous abortion in hospital staff engaged in sterilising instruments with chemical agents. Br Med J 1982;285:1461-3.

7 Harkonen H, Holmberg PC. Obstetric histories of women occupationally exposed to styrene. Scand J Work Environ Health 1982;8:74-7.

8 Kline J, Stein Z. Spontaneous abortion. In: Bracken MC, ed. Perinatal epidemiology. New York: Oxford University Press, 1984:23-51

9 Taylor PR, Lawrence CE, Hwang HL, Paulson AS. Polychlorinated biphenyls: influence on birthweight and gestation. Am J Public Health 1984;74:1153-4.

10 Hatch $\mathbf{M}$, Kline J, Stein Z. Power considerations in studies of reproductive effects of vinyl chloride and some structural analogs. Environ Health Perspect 1981;41:195-201.

11 Sheikh K. Adverse health effects of ethylene oxide and occupational exposure limits. Am J Ind Med 1984;6:117-27.

12 Townsend JC, Bonder KM, Van Peenen PFD, Olson RD, Cook RR. Survey of reproductive events of wives of employees exposed to chlorinated dioxins. Am J Epidemiol 1982; 115:659-713.

13 Roan CC, Matanoski GE. McIlnay CQ, et al. Spontaneous abortions, still births, and birth defects in families of agricultural pilots. Arch Environ Health 1984;39:56-60.

14 Hemminki K, Axelson O, Niemi ML, Ahlborg G. Assessment of methods and results of reproductive occupational epidemiology: spontaneous abortions and malformations in the offspring of working women. Am J Ind Med 1983;4:293-307.

15 Austin SG. Spontaneous abortions in hospital sterilising staff. Br Med J 1983;286:1976.

16 Roman E, Alberman E. Spontaneous abortion, gravidity, pregnancy order, age, and pregnancy interval. In: Porter IH, Hook EB, eds. Human embryonic and fetal death. New York: Academic Press, 1980:129-41.

17 Roman E, Stevenson AC. Spontaneous abortion. In: Barron SL, Thomson AM, eds. Obstetrical epidemiology. New York: Academic Press, 1983:61-87.

18 Axelsson GL. Selection bias in studies of spontaneous abortion among occupational groups. J Occup Med 1984;26:525-8. 